\title{
Synthesis, Stability, Spectral and Characterization of Mercury (II) Complexes with a Novel Bis-Schiff base Ligand
}

\author{
M. H. Moustafa*, A. Abd-Elnaeem and O. A. Abbas \\ Department of Chemistry, Faculty of Science, Al-Azhar \\ University, Assiut Branch, Assiut, Egypt.
}

\begin{abstract}
A
NEW reagent, (2E,2'Z) -2,2'- (3- ((E)- (2-hydroxyphenyl) diazenyl) pentane-2,4- diylidene) bis (hydrazinecarbothioamide) (OPTS) was synthesized and studied. Acid-base, spectrophotometric properties of OPTS were studied in 50\% ethanolwater mixture solutions at $\mathrm{pH} 3-11$. Dissociation constants of the reagent OPTS have been determined by spectrophotometry and potentiometric titrations: $\mathrm{pK}_{1}=9.60 \pm 0.02 ; \mathrm{pK}_{2}=10.45 \pm 0.05$ in its computational and graphical versions at an ionic strength $0.1 \mathrm{M}$. The stability constants of the $\mathrm{Hg}$-OPTS are $\log \mathrm{K}_{1}=6.18 \pm 0.04$ and $\log \mathrm{K}_{2}=5.22 \pm 0.05$. The reaction of $\mathrm{Hg}$ (II) with OPTS gives mononuclear complex in $50 \%$ ethanol - water mixture solution with $\lambda_{\max }=448 \mathrm{~nm}$ at $\mathrm{pH} 8.5$. The effects of foreign ions and masking agents on the determination of $\mathrm{Hg}(\mathrm{II})$ with the new reagent were monitored. The mono complex obey the Beer law in the $\mathrm{Hg}(\mathrm{II})$ concentration range $5.10-50.17 \mathrm{mg} / 25 \mathrm{ml}$. Molar absorption coefficients was determined. In this paper, we report the synthesis of the novel $\mathrm{Hg}(\mathrm{II})$ complexes with OPTS. The complexes were characterized by UV-vis and IR spectroscopy, elemental analysis, molar conductivity and thermal decomposition.
\end{abstract}

Keywords: Mercury (II) complexes, Bis (thiosemicarbazone), Synthesis, Physico-chemical characterization and Thermal decomposition.

Antitumor activity of thiosemicarbazone was reported first by Domagk ${ }^{(1)}$. Because of their biological activity and analytical application, thiosemicarbazides and thiosemicarbazones, as well as their metal complexes have been the subject of many studies ${ }^{(2-4)}$. The metal complexes show more activity as compared to the free thiosemicarbazones and semicarbazones. They may have numerous applications, e.g. anticancer ${ }^{(5,6)}$, fungicides, antibacterial ${ }^{(7,8)}$, antiviral ${ }^{(9,10)}$, antifungal ${ }^{(11-12)}$, anti $\mathrm{HIV}^{(13)}$, antitumour activity ${ }^{(14)}$, antimalarial ${ }^{(15,16)}$ and other biological activities ${ }^{(17-19)}$. This paper describes the synthesis of one of the newer bis (thiosemicarbazone) reagent (2E,2'Z)-2,2'-(3-((E)- (2-hydroxyphenyl) diazenyl) pentane-2,4-diylidene) bis (hydrazinecarbothioamide) (OPTS). The acid-base equilibria of the ligand (OPTS) were investigated. We also describe here the synthesis and some physico-chemical and structural characteristics of its first complexes with $\mathrm{Hg}(\mathrm{II})$, as well as two new $\mathrm{Hg}$ (II) complexes with OPTS.

*E- mail: mahhassan1959@yahoo.com 
The bis-Schiff base ligand, $\mathrm{H}_{2} \mathrm{~L}$, was synthesized by condensing ohydroxyphenyl azo acetylacetone with thiosemicarbazide, on refluxing in stoichiometry of $1: 2$. The first $\mathrm{Hg}$ (II) complexes with thiosemicarbazide-based derivatives have raised considerable interest due to their analytical properties. On the basis of elemental analysis, absorption spectra and potentiometry the metal to ligand stoichiometry of 1:1 has been proposed for these complexes. The proposed structure for these complexes has the support of IR and UV-vis spectra.

\section{Experimental}

Reagents

All chemicals were Analar grade. O-aminophenol, acetylacetone and thiosemicarbazide which were used for the preparation of the ligand OPTS was from Sigma-Aldrich Chemicals Co., USA and were used as received. The metal salt mercuric chloride $\left(\mathrm{HgCl}_{2}\right)$ was from Merck (Germany) and were used without purification. Perchloric acid $\left(\mathrm{HCLO}_{4}\right)$, sodium perchlorate $\left(\mathrm{NaClO}_{4}\right)$, sodium hydroxide $(\mathrm{NaOH})$, potassium hydrophethalate $\left(\mathrm{KHC}_{8} \mathrm{H}_{4} \mathrm{O}_{4}\right)$, borax $\left(\mathrm{Na}_{2} \mathrm{~B}_{4} \mathrm{O}_{7} \cdot 10 \mathrm{H}_{2} \mathrm{O}\right)$, DMF and ethanol of Analar grade were obtained from Merck (Germany).

\section{Physical measurements}

$\mathrm{pH}$ measurements were carried out using a Corning $215 \mathrm{pH}$ meter with a combined glass electrode. The glass electrode was calibrated before each titration with two Merck standard buffer solutions, first with the $\mathrm{pH} 7.0$ followed by a $\mathrm{pH}$ 4.0 at $25^{\circ} \mathrm{C}$ by coupling the titration cell with a thermostatic bath set at this temperature.

The electronic spectra of solutions of the ligand OPTS and its mercury complexes were recorded on a Perkin-Elmer (Lambda 35) computerized spectrophotometer equipped with $1 \mathrm{~cm}$ matched quartz cells. IR-spectra were recorded using a Fourier transform infrared spectrometer (FT-IR) in the region $400-4000 \mathrm{~cm}^{-1}$ with Jasko 480 spectrometer using the potassium bromide disk technique. Elemental analysis was carried out by the unit of micro analyses on a Perkin-Elmer $240 \mathrm{C}$ instrument. NMR spectra were recorded in DMSO on Varian EM-360 L, 60 MHz NMR spectrometer and JEOL FX 90 Q Fourier transform NMR. Molar conductivities of freshly-prepared $1 \times 10^{-3} \mathrm{M}$ solution were measured on a Jenway 4320 conductivity meter. Mass spectra were performed by Shimadzu- GCMS-OP 1000 Ex using direct inlet system. Thermograrimetric analysis TG was carried out with a Schimadzu DTG-60 H. A simultaneous DTA-TG apparatus at a heating rate of $10^{\circ} \mathrm{C} / \mathrm{min}$ in nitrogen atmosphere.

\section{Preparations of the ligand}

The compound o-hydroxyphenyl azo acetyl acetone (o-HPAA) was synthesized by a known procedure ${ }^{(20)}$, adopting a reported earlier procedure ${ }^{(21)}$. The reaction of two molecules of diamines and ketone ensures giving a 
compound containing two imino groups $-\mathrm{CH}=\mathrm{N}-$ in each unit. Scheme 1, adopts a procedure of preparing the ligand (2E,2'Z)-2,2'-(3-((E)-(2hydroxyphenyl) diazenyl) pentane-2,4-diylidene) bis (hydrazinecarbothioamide) (OPTS). A solution of o-hydroxyphenyl azo acetyl acetone $(0.02 \mathrm{M})$ in $20 \mathrm{ml}$ of ethanol was continuously stirred with an ethanolic solution of thiosemicarbazide $(0.04 \mathrm{M})$, the reaction mixture was heated under reflux for $6 \mathrm{hr}$ on a water bath at $60{ }^{\circ} \mathrm{C}$. The resulting solution mixture was kept for one day. After this time, the formed yellowish powder of the bis(thiosemicarbazone) ligand was collected. The solid formed was filtered and washed with cold $\mathrm{EtOH}$ and dried in vacuo. $\mathrm{H}_{2} \mathrm{~L}$ : Anal. Found: C, 42.82; $\mathrm{H}, 4.30 ; \mathrm{N}, 29.97 ; \mathrm{S}, 17.47 . \mathrm{C}_{13} \mathrm{H}_{18} \mathrm{~N}_{8} \mathrm{OS}_{2}$ requires: 42.84; H, 4.31; N, 29.98; S, 17.48\%; mass spectrum: $m / z 365.77$ (Fig. 1), yields $76 \%$ m.p 290. ${ }^{1} \mathrm{H}$ NMR spectra of the Schiff base ligand (Fig. 2) were performed in DMSO and the chemical shifts in ppm were recorded as follows: $\delta=2.4 \mathrm{ppm}$ $(\mathrm{s}, 3 \mathrm{H}, \mathrm{CH} 3-\mathrm{C}=\mathrm{N}), \delta=11.35 \mathrm{ppm}(\mathrm{s}, 1 \mathrm{H},(\mathrm{s}, 1 \mathrm{H}, \mathrm{OH}), \delta=10.45 \mathrm{ppm}(\mathrm{s}, 2 \mathrm{H}$, $\mathrm{NH}-\mathrm{C}=\mathrm{S}), \delta=7.66 \mathrm{ppm}(\mathrm{s}, 2 \mathrm{H}, \mathrm{NH} 2-\mathrm{C}=\mathrm{S}), \delta=7.27,7.25,7.01,6.95 \mathrm{ppm}(\mathrm{m}$, $4 \mathrm{H}, \mathrm{Ar}-\mathrm{H})$. (Fig. 2). ${ }^{1} \mathrm{H}$ NMR spectra $(\delta, \mathrm{ppm})$ in DMSO-d6 solvent of the (a) Schiff base, $\mathrm{H}_{2} \mathrm{~L}$, ligand (b) Schiff base, $\mathrm{H}_{2} \mathrm{~L}$, ligand after addition of $\mathrm{D}_{2} \mathrm{O}(*)$ $\mathrm{NH}, \mathrm{NH}_{2}$ and $\mathrm{OH}$ bands which disappeared after the addition of $\mathrm{D}_{2} \mathrm{O}$ solvent, where (a) NMR for ligand, $\mathrm{D}_{2} \mathrm{O}$ NMR for ligand, (b) Notes that the disappearance for $(\mathrm{OH})$ and $(\mathrm{NH})$ in Fig. 2(b).<smiles>CC(=O)C(N=Nc1ccccc1O)C(C)=O</smiles>

Scheme 1. Synthesis strategy for the preparation of OPTS $\left(\mathrm{H}_{2} \mathrm{~L}\right)$.

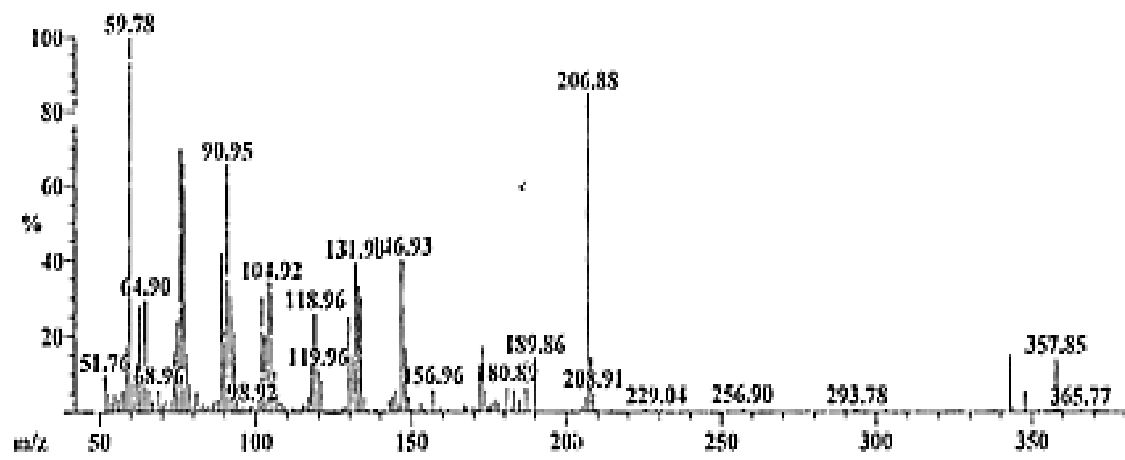

Fig. 1. Mass spectra of bis(thiosemicarbazone)( OPTS). 


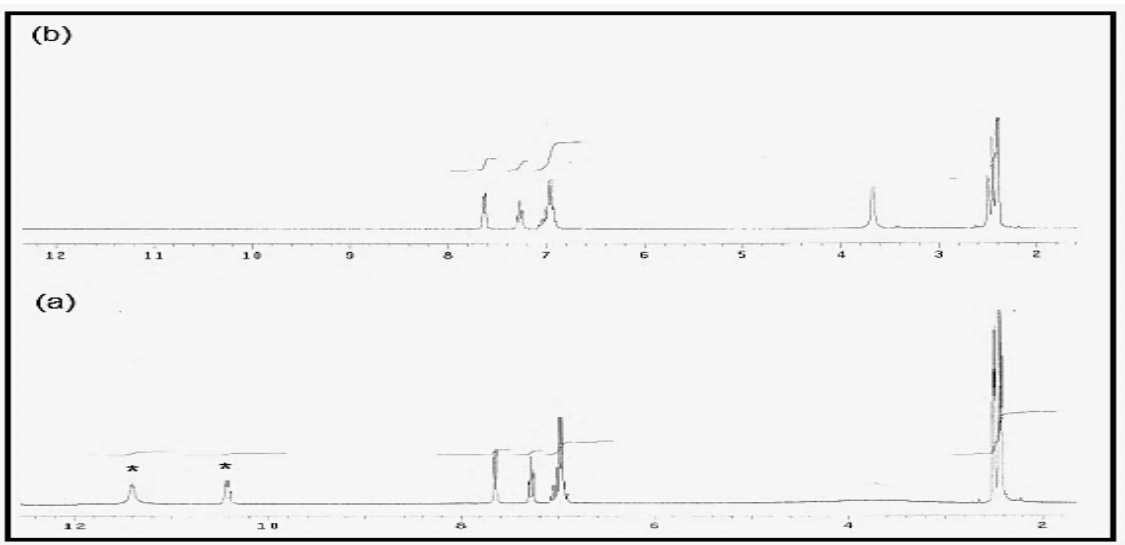

Fig. 2. ${ }^{1}$ H NMR spectra of bis(thiosemicarbazone)( OPTS).

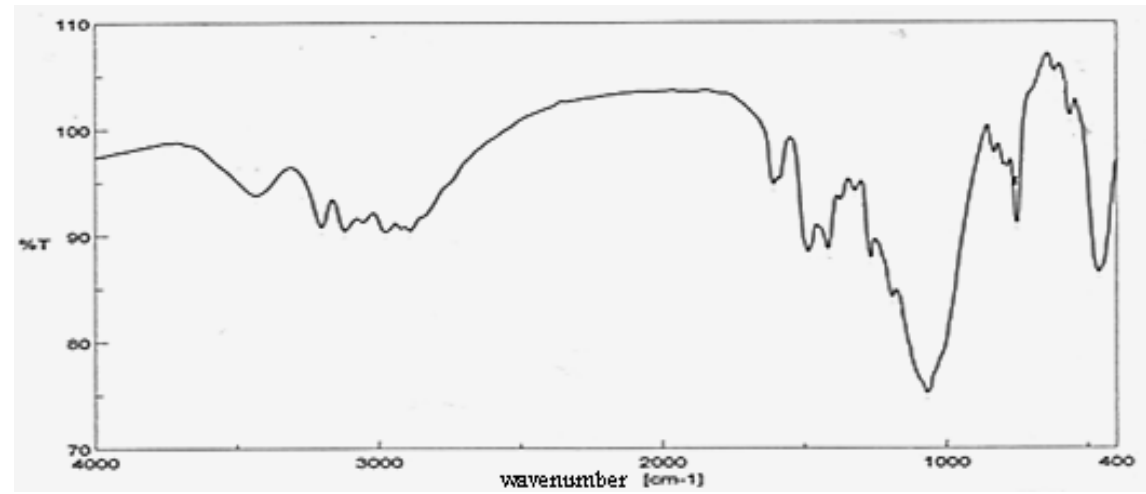

Fig. 3. FT-IR spectra of bis(thiosemicarbazone)( OPTS).

Preparation of mercury(II) complexes

A general procedure was followed: Equimolar amounts of a warm aqueous $(20 \mathrm{ml})$ solution of corresponding metal salt $(0.01 \mathrm{~mol}$.) was added to a warm ethanolic solution $(20 \mathrm{ml})$ of the ligand OPTS $(0.01 \mathrm{~mol}$.). The mixture was heated under reflux with stirring for 6-7 hr. On cooling a black coloured complex precipitated, which was filtered, washed with cold ethanol and dried in vacuo over $\mathrm{P}_{4} \mathrm{O}_{10}$ (yield 62\%). HgL; Anal. Found: C, 27.51; H, 2.80; N, 19.64, $\mathrm{C}_{13} \mathrm{H}_{16} \mathrm{ON}_{8} \mathrm{HgS}_{2}$, requires: C, 27.52; H, 2.82; N, 19.76; S, 11.18

\section{Results and Discussion}

pH metric studies

The acid- base properties of the bis-Schiff base ligand $\left.2 \mathrm{E}, 2^{\prime} \mathrm{Z}\right)-2,2^{\prime}-(3-((\mathrm{E})-$ (2-hydroxyphenyl)diazenyl)pentane-2,4-diylidene)bis(hydrazinecarbothioamide) OPTS (L) in $50 \%$ ethanol-water mixture solution indicated that the predominant

Egypt. J. Chem. 54, No.5 (2011) 
form of the ligand is the neutral species; which undergoes stepwise ionization on increasing the $\mathrm{pH}$ of solution. The protonation equilibria of ligand $\left(\mathrm{H}_{2} \mathrm{~L}\right)$ can be represented by Eq. (1) and (2):

$$
\begin{aligned}
& \mathrm{H}_{2} \mathrm{~L} \rightleftharpoons \mathrm{HL}^{-}+\mathrm{H}^{+} \ldots \ldots \ldots \\
& \mathrm{HL}^{-} \rightleftharpoons \mathrm{L}^{-}+\mathrm{H}^{+} \ldots \ldots \ldots \ldots . .
\end{aligned}
$$

The $\bar{n}_{\mathrm{A}}, \bar{n}$ and $\mathrm{pL}$ values were calculated at different $\mathrm{pH}$ values using the known equations of Irving and Rossotti ${ }^{(22)}$. The protons dissociation constants were determined by plotting $\bar{n}_{\mathrm{A}}$ against the $\mathrm{pH}$ giving the proton ligand formation curve. The ionization constants of the ligand $\left(\log K_{1}\right.$ and or $\left.\log K_{2}\right)$ were calculated at $\bar{n}_{\mathrm{A}}$ values of 0.5 or 1.5. The following values of dissociation constants of OPTS were found by potentiometry: $\mathrm{pK}_{1}=9.60 \pm 0.02$ and $\mathrm{pK}_{2}=10.45 \pm 0.05$ in $\mathrm{NaClO} 4$ as supporting electrolyte $[\mathrm{I}=0.1 \mathrm{M}]$. The reagent OPTS is considered as $\mathrm{H}_{2} \mathrm{~L}$ ligand and the following species are involved in the acid-base forms $\mathrm{H}_{2} \mathrm{~L}, \mathrm{HL}^{-}, \mathrm{L}^{--}$(Scheme 2). The central NH group can deprotonate rapidly and delocalise with the terminal $\mathrm{C}=\mathrm{S}$ groups, forming an enamic form in the conjugate anionic ligand. As a consequence there are several resonance structures for the $\mathrm{N}$-substituted thiosemicarbazide anion in which the sulphur atom is anionic ${ }^{(23,24)}$. The dianionic form resulting from deprotonation of the two mercapto groups. The potentiometric titration curve for OPTS (Fig. 4) in the form $\mathrm{H}_{2} \mathrm{~L}$ shows two inflections at $\mathrm{a}=1$, followed by a moderate inflection at $\mathrm{a}=2(\mathrm{a}=$ moles of base added per mole of ligand $)$ corresponding to the stepwise dissociation constants of the ligand. The titration curve for a system containing 1:1 molar ratio of $\mathrm{Hg}(\mathrm{II})$ and OPTS exhibits one inflections at $\mathrm{m}=1(\mathrm{~m}=$ moles of base added per mole of metal ion) indicating the formation of mono-binary complexes. The formation and stability of binary complexes with OPTS in 1:1 molar ratio were studied by potentiometric $\mathrm{pH}$ titration in $50 \%(\mathrm{v} / \mathrm{v})$ ethanolwater medium, ionic strength $\mathrm{I}=0.1 \mathrm{M}(\mathrm{NaClO} 4)$, temp. $=25^{\circ} \mathrm{C}$. The $\bar{n}$ and $\mathrm{pL}$ values were calculated at different points in the $\mathrm{pH}$ range of study. The metal-ligand stability constants were obtained from the curves drawn between $\bar{n}$ and $\mathrm{pL}$.

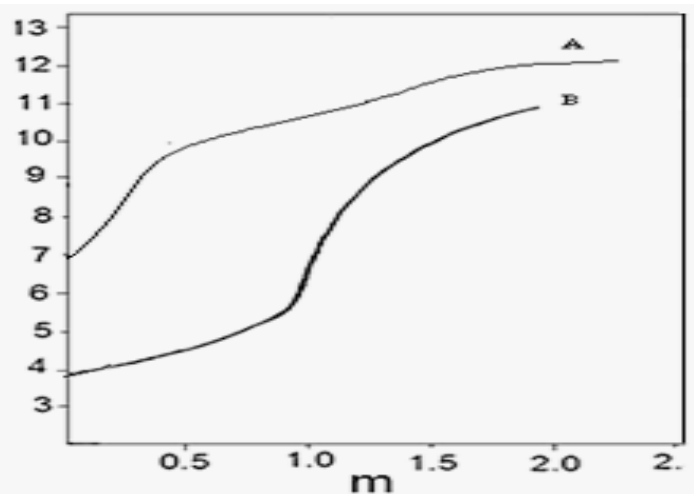

Fig. 4. Potentiometric titration curves of: A) diprotonated ligand OPTS, and B) Hg(II)- OPTS binary systems [ $\mathrm{m}=$ moles of alkali per mole of metal ion ]. The abscissa represents the moles of alkali added per mole of ligand.

Egypt. J. Chem. 54, No.5 (2011) 
The predicted structure for the ligand OPTS is:<smiles>CC(=NNC(N)=S)C(N=Nc1ccccc1O)C(C)=NNC(N)=S</smiles>

$\mathrm{H}_{2} \mathrm{~L}$<smiles>C/C(=N/N=C(/N)S)C(N=Nc1ccccc1O)/C(C)=N/N=C(\N)[S-]</smiles>

$\mathbf{L}^{-}$<smiles>C/C(=N/N=C(/N)S)C(N=Nc1ccccc1O)/C(C)=N/O</smiles>

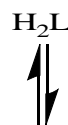<smiles>C/C(=N/N=C(N)S)C(N=Nc1ccccc1O)/C(C)=N/N=C(\N)S</smiles>

$\mathrm{HL}^{-}$

Scheme 2. Structural representations of $\mathrm{H}_{2} \mathrm{~L}, \mathrm{HL}^{-}$and $\mathrm{L}^{-*}$.

Potentiometric determination of stoichiometry of the binary complexes proved that the ligand (OPTS) form 1:1 (M:L) binary complex. The stability constant for the binary $\mathrm{Hg}$ - OPTS) complexes were calculated from titration curves in which the metal to ligand ratio was 1:2 and the concentration of each metal ion was $8 \times 10^{-5} \mathrm{M}$. From the formation curves the stepwise stability constants of binary chelates were determined and are listed in Table 1. The complexed species found in this work for OPTS and the studied metal ions can be represented by Eq. 3:

$$
\mathrm{M}+\mathrm{L} \rightleftharpoons \mathrm{ML}, \quad k_{M L}^{M}=\frac{[M L]}{[M] .[L]},
$$

TABLE 1. The ionization constants of the ligand OPTS and the formation constants of their $\mathrm{Hg}(\mathrm{II})$ complexes.

\begin{tabular}{|c|c|c|c|c|c|}
\hline \multirow[t]{2}{*}{ Compound } & \multicolumn{2}{|c|}{$\mathbf{H}^{+}$} & \multicolumn{3}{|c|}{ HgL } \\
\hline & $\mathrm{p} K_{1}$ & $\mathrm{p} K_{2}$ & $\log k_{M L}^{M}$ & $\log k_{M L_{2}}^{M L}$ & $\log \beta_{M L_{2}}^{M L}$ \\
\hline OPTS & 10.45 & 9.60 & 6.18 & 5.22 & 11,40 \\
\hline
\end{tabular}

$\beta_{\mathrm{a}}$ is the overall stability constant.

Egypt. J. Chem. 54, No.5 (2011) 
Electronic spectra

The spectra of the neutral forms of the ligand OPTS were recorded over the available region in $50 \%(\mathrm{v} / \mathrm{v})$ ethanol-water medium, from 270 to $800 \mathrm{~nm}$, as well in the presence of $\mathrm{NaClO} 4[\mathrm{I}=0.1 \mathrm{M}]$ as supporting electrolyte in the measurements. The absorption spectra of $2.5 \times 10^{-4} \mathrm{M}$ solution of the reagent (OPTS) were recorded as a function $\mathrm{A}=\mathrm{F}(\lambda)$ for various $\mathrm{pH}$ values in the presence of 50\% ethanol. The spectra showed absorption bands with the $\mathrm{pH}$ range 5-9. The strong broad bands were observed between $(300-700 \mathrm{~nm})$. The spectra of the ligand are characterized by a band at $340 \mathrm{~nm}$ (Fig. 5). The absorbance versus $\mathrm{pH}$ graphs were interpreted according to the relationship which described in literature ${ }^{(25)}$. The dissociation constants of OPTS were determined spectrophotometrically beside the above study in water-ethanol and $\mathrm{I}=0.1 \mathrm{M} \mathrm{NaClO}_{4}$. The $\mathrm{pK}$ values were calculated from the variation of the absorbance with $\mathrm{pH}$ according to Phillips and Merrit ${ }^{(26)}$ and Sommer ${ }^{(27)}$. From the data obtained by each method, estimation of the acidity constants of OPTS and the complex formation constants were determined using the SUPERQUAD program ${ }^{(28)}$. The program has been used to calculate acidity constants in systems previously studied ${ }^{(29-31)}$. The final results for $\mathrm{pK}$ values are the average of six pairs of independent titrations. Molar absorption coefficient of the spectra of the complexes were also recorded under similar conditions $\left(1800 \mathrm{l} \mathrm{mol}^{-1} \mathrm{~cm}^{-1}\right)$. The prominent strong bands of the reagent OPTS with the highest absorbance gives molar absorption coefficient equal to $148001 \mathrm{~mol}^{-1} \mathrm{~cm}^{-1}$ (Fig. 6). Bands in the range $300-400 \mathrm{~nm}$ are assigned to a combination of intraligand and LMCT absorptions ${ }^{(32)}$. It can be seen in Fig. 6 that the absorption maxima at $448 \mathrm{~nm}$ of mercury mono complex exhibit bathochromic shifts relative to the absorption maximum of the reagent. The solution spectra were recorded in equimolar solutions and in solutions containing an excess of the reagent or the metal ions. The absorption spectra reflect the formation of one complex species and the existence of chelate equilibrium in the studied $\mathrm{pH}$ range. The absorption spectra for equimolar solutions and those containing a preponderance of $\mathrm{M}^{\mathrm{II}}$ are analogous and exhibit an absorption band at $448 \mathrm{~nm}$ for $\mathrm{Hg}^{\text {II }}$. The absorption bands are observed in the $\mathrm{pH}$ range 4-9.9. The absorption bands characterizing the $\mathrm{Hg}^{\mathrm{II}}$ complex species in the $\mathrm{pH}$ studied range are shown in Fig. 6. The absorbance versus $\mathrm{pH}$ graphs for $\mathrm{Hg}$-OPTS were interpreted using relations derived by Sommer et al. ${ }^{(32,33)}$. The absorbance vs. $\mathrm{pH}$ graphs were analyzed graphically as described previously ${ }^{(34)}$ and once complexation equilibria established, in solutions of the complex Hg-OPTS species within the $\mathrm{pH}$ range studied for the complex. The acidity constants and stability constants of the complex were determind and are the same as those calculated by potentiometry. The titrations were carried out at four OPTS/ $\mathrm{M}^{\mathrm{II}}$ ratios. The ligand/metal ratio was varied from 4:1 to 1:1. The absorption spectrum (Fig. 6) shows the maximum absorbance of the reaction of an aqueous $\mathrm{Hg}(\mathrm{II})$ solution with an ethanolic solution of OPTS at $\mathrm{pH} 8.5$. The absorbance versus $\mathrm{pH}$ graph for solution (Eq. 6-8) were determined under the same conditions as used in the experiments for those containing Hg-OPTS complex indicating the presence of one system only of complex equilibria at wavelength $448 \mathrm{~nm}$. The effect of $\mathrm{pH}$ absorption spectra of the binary complexes under investigation limited the 
optimal reaction conditions for synthesis of the solid complex. The formation constant for the following equilibria in binary systems containing $\mathrm{Hg}$-OPTS:

$$
\mathrm{Hg}^{2+}+\left(\text { OPTS }-\mathrm{H}_{2}\right) \rightleftharpoons[\mathrm{Hg}(\mathrm{OPTS})]+2 \mathrm{H}^{+}
$$

were calculated considering the relevant data or the acid dissociation constants and the cumulative binary constants.

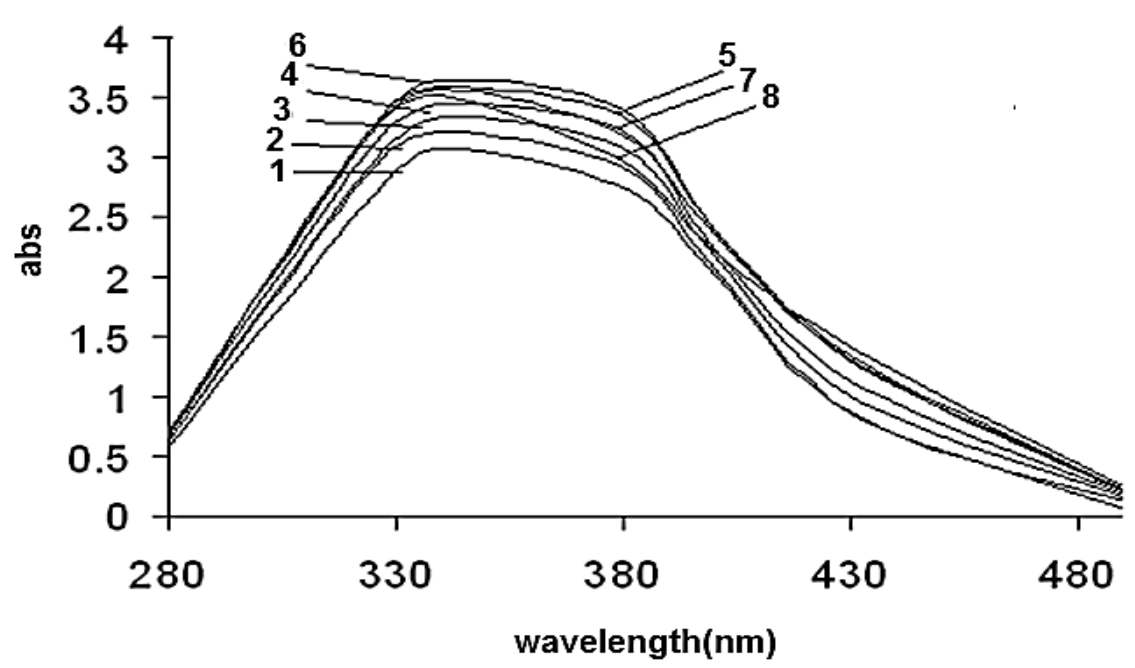

Fig. 5. Absorption spectra of ligand (OPTS) pH: 1(3), 2(4), 3(5), 4(6), 5(7), 6(8), 7(8. 5), 8(9) .

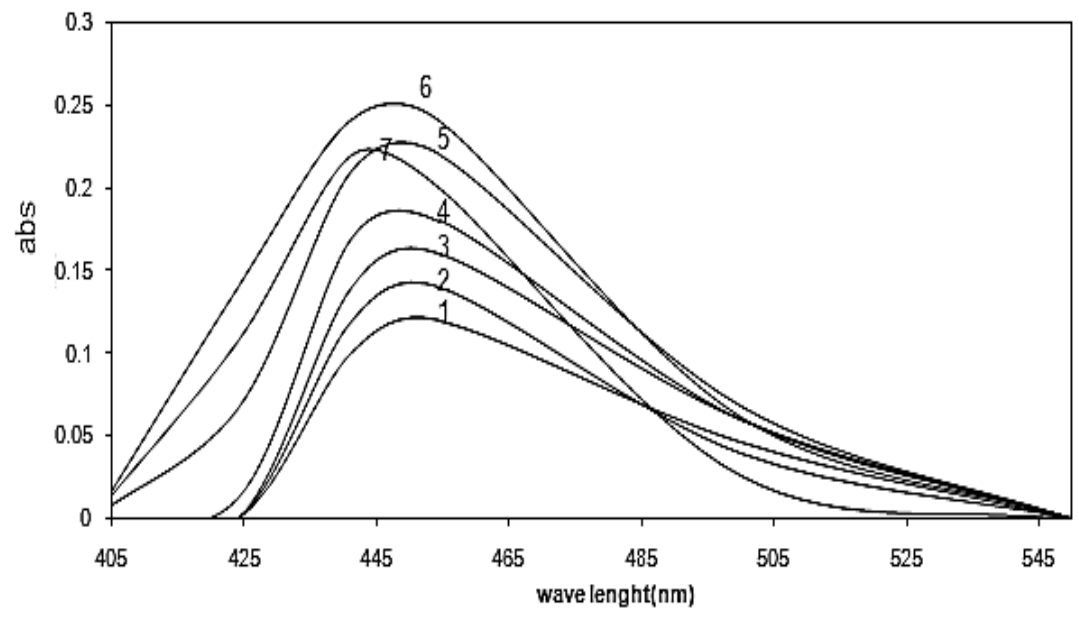

Fig . 6. Absorption spectra of Hg-OPTS complex; $C_{L}=C_{M}=2.5 \times 10^{-4} \mathrm{M}, I=1.0 \mathrm{M}$ $\left(\mathrm{NaClO}_{4}\right), \mathrm{pH} 1(5), 2(5.5), 3(6), 4(6.5), 5(7), 6(8.5), 7(9.2)$.

Egypt. J. Chem. 54, No.5 (2011) 
Stoichiometry of the complexes

Jobs method of continuous variation ${ }^{(35,36)}$ was applied to establish the composition of the complexes $\mathrm{Hg}^{\mathrm{II}}-\mathrm{OPTS}$. In solutions with $\mathrm{C}_{\mathrm{o}}=\mathrm{C}_{\mathrm{M}}+\mathrm{C}_{\mathrm{L}}=$ $3.6 \times 10^{-3} \mathrm{~mol} \mathrm{l}^{-1}$ at $\mathrm{pH} 8.5$, the maximum of Job plot corresponds to a component ratio of 1:1 (metal to ligand). The plot of absorbance versus mole fraction of $\mathrm{Hg}^{\mathrm{II}}$ shows a maximum at 0.5 , suggesting the formation of a 1:1 (M:L) complex. The composition of the complexes was also confirmed by applying the mole ratio method $^{(37)}$.

\section{Calibaration graph and reproducibility}

Under the optimum conditions, a linear calibration graph for Hg-TAR complex was obtained up to a concentration of $45.02 \mu \mathrm{g} / 25 \mathrm{ml}$ mercury with a molar absorptivity of $7201 \mathrm{~mol}^{-1} \mathrm{~cm}^{-1}$ at $448 \mathrm{~nm}$. A Ringbom plot showed that the optimum concentration range for the determination of $\mathrm{Hg}(\mathrm{II})$ was 1.35 - 41.98 $\mu \mathrm{g} / 25 \mathrm{ml}$. Sandell's sensitivity index ${ }^{(38)}$ of the reaction was found to be $4.76 \times 10^{-3} \mathrm{ng}$ $\mathrm{cm}^{-1}$. The relative standard deviation (RSD) was $0.76 \%$ for nine determinations, each having a mercury concentration $15.75 \mu \mathrm{g} \mathrm{ml}^{-1}$. The reproducibility of the method was determined by testing two series of solutions having mercury concentrations of 7.54 and $17.85 \mu \mathrm{g} \mathrm{ml}^{-1}$.

\section{Molar conductivity}

The molar conductivity of the freshly prepared Hg-OPTS complex in DNF solution, corresponding to $1: 1$ molar ratio was $7.8 \mathrm{ohm} \mathrm{cm}^{-1}$. The data reveal that the complex is none-electrolyte type.

\section{IR absorption spectra}

The character of the IR spectra is in accordance with the established structure of the ligand (Fig. 3) and Hg-OPTS complex (Fig. 7). Their prominent feature is the presence of $v_{(\mathrm{OH})}$ stretching vibration band at $3435 \mathrm{~cm}^{-1}$; which means that the phenolic group is not coordinated. This band may be overlapping with the bands corresponding to the stretching vibration of $-\mathrm{NH}_{2}$ group. The IR spectra of OPTS, show two bands at 3202 and $3120 \mathrm{~cm}^{-1}$ which are assigned to symmetric and asymmetric vibrations of $v_{(\mathrm{NH})}$ and the band at $2977 \mathrm{~cm}^{-1}$ assigned to vibrations of $v_{(\mathrm{C}-\mathrm{H})}$. The band at $2880 \mathrm{~cm}^{-1}$, attributed to $v_{(\mathrm{SH})}$ mercapto mode disappears in the spectrum of Hg-OPTS complex. This indicates the presence of thiol-tautomer in the solid state. Another important band occurs at $1606 \mathrm{~cm}^{-1}$ in both spectra of the ligand and complex, attributed to $v_{(\mathrm{C}=\mathrm{N})}$ stretching mode; indicating none involvement of the $\mathrm{N}$-atom of the azomethine in coordination. The thioamide [N-HCS] group has four bands observed in the spectrum of the ligand at 1486, 1418, 1322 and $830 \mathrm{~cm}^{-1}$. These bands have contribution from $\left[v_{(\mathrm{C}-\mathrm{H})}+v_{(\mathrm{N}-\mathrm{H})}\right],\left[v_{(\mathrm{C}-\mathrm{S})}+v_{(\mathrm{C}-\mathrm{N})}+v_{(\mathrm{C}-\mathrm{H})]},\left[v_{(\mathrm{C}-\mathrm{N})}+v_{(\mathrm{C}-\mathrm{S})}\right]\right.$ and $\left[v_{(\mathrm{C}-\mathrm{S})}\right]$, respectively ${ }^{(39)}$. These bands are observed at 1499,1411 and $834 \mathrm{~cm}^{-1}$ in complex spectrum. The absorption bands due to $v_{(\mathrm{C}=\mathrm{S})}$ stretching are in the region between 1067 and $1267 \mathrm{~cm}^{-1}$. In principle, the ligand can exhibit thione/thiol tautomerism, since it contains a thioamide $\mathrm{NH}-\mathrm{C}=\mathrm{S}$ functional group. In addition, OPTS exhibits characteristic $(\mathrm{C}=\mathrm{S})$ band at $790 \mathrm{~cm}^{-1}$, which is red shifted by $20 \mathrm{~cm}^{-1}$ in the spectra of metal complex suggesting deprotonation of 
the $2(\mathrm{~S}-\mathrm{H})$ proton; thus generating thiolato sulfur which is one of the coordinating sites. This proved that OPTS may bind through thione $(\mathrm{C}=\mathrm{S})$, thiol $(-\mathrm{C}-\mathrm{SH})$ or both as a consequence of tautomerism. A new band appears at 991 $\mathrm{cm}^{-1}$ corresponding to the ring breathring. Thus, the infrared spectra reveal that OPTS bis (thiosemicarbazone) behaves as dibasic, bisbidentate ligand, coordinating through thiol sulphur and azomethine nitrogen. A summary of the FTIR spectral data is given in Table 2.

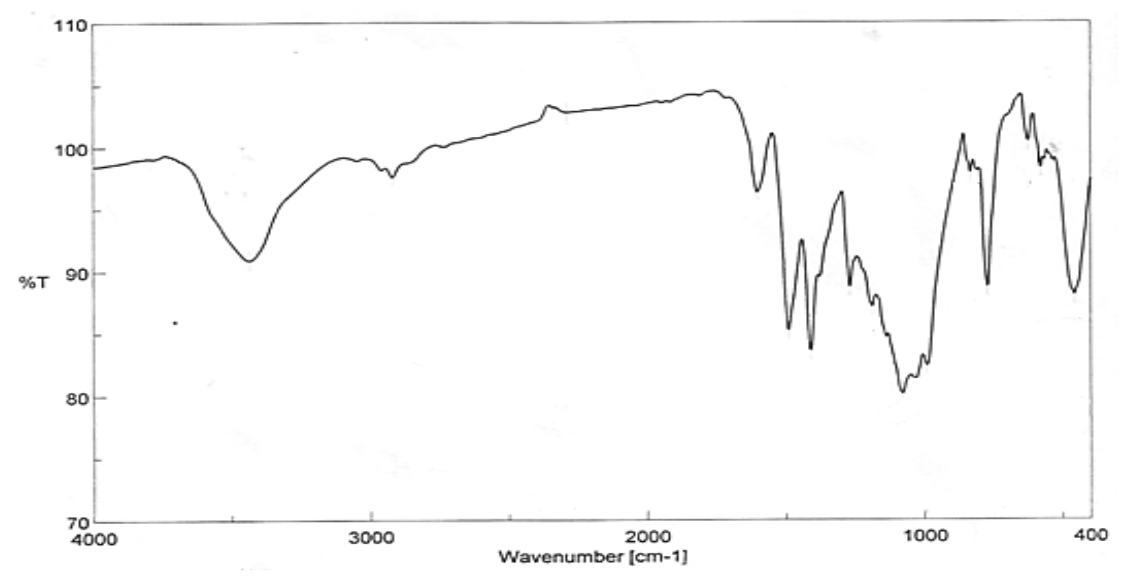

Fig. 7. FTIR absorption spectrum of complex Hg-OPTS.

TABLE 2. Infrared spectral data for OPTS ligands and their $\mathrm{Hg}(\mathrm{II})$ complex $\left(\mathrm{cm}^{-1}\right)$.

\begin{tabular}{|c|c|c|c|c|c|c|c|c|}
\hline Compound & $\begin{array}{c}\boldsymbol{v}(\mathbf{O H}) \\
\text { and } \\
\mathbf{v}\left(\mathbf{N H}_{2}\right)\end{array}$ & $\boldsymbol{v}(\mathbf{N H})$ & $\mathbf{v}(\mathbf{C}=\mathbf{N})$ & $\boldsymbol{v}(\mathbf{N}=\mathbf{N})$ & $\mathbf{v}(\mathbf{C}=\mathbf{S})$ & $\mathbf{v}(\mathbf{N}-\mathbf{C}=\mathbf{N})$ & $\boldsymbol{v}(\mathbf{C}-\mathbf{S})$ & $\begin{array}{c}\boldsymbol{v}(\mathbf{M}- \\
\mathbf{N})\end{array}$ \\
\hline OPTS & $\begin{array}{c}3435, \\
3202\end{array}$ & 3120 & 1608 & 1486 & 1486 & 1418 & $\begin{array}{c}1067, \\
790\end{array}$ & - \\
\hline Hg-OPTS & 3435 & - & 1606 & 1491 & 1491 & - & $\begin{array}{c}1078, \\
771\end{array}$ & 458 \\
\hline
\end{tabular}

\section{Thermal analysis}

Heating of $\mathrm{Hg}$-OPTS complex in the temperature range from room temperature up to $800{ }^{\circ} \mathrm{C}$ under nitrogen and the resulting TG and DTA curves are presented in Fig. 8. It is accompanied by two stages of mass loss. The first loss in the temperature range from room temperature up to $250{ }^{\circ} \mathrm{C}$ started with the removal of $2(\mathrm{HNCSNHNH})$ and ending at $70^{\circ} \mathrm{C}{ }^{(40)}$, was followed by the complete decomposition of the ligand. The observed second mass loss was connected with thermolysis of the complex remaining ${ }^{(41)}$. The second step starts

Egypt. J. Chem. 54, No.5 (2011) 
immediately after first step and continues until complete decomposition of the ligand. Although decomposed fragments of the ligands could not be approximated due to continuous weight loss, the total \% weight loss corresponds to the loss of the respective ligand after considering the transfer of the oxygen atom to the mercury and residue corresponds to the respective metal and the formation of the end product as mercuric oxide $\mathrm{HgO}$. The decomposition of the complex was completed at $\geq 750^{\circ} \mathrm{C}$.

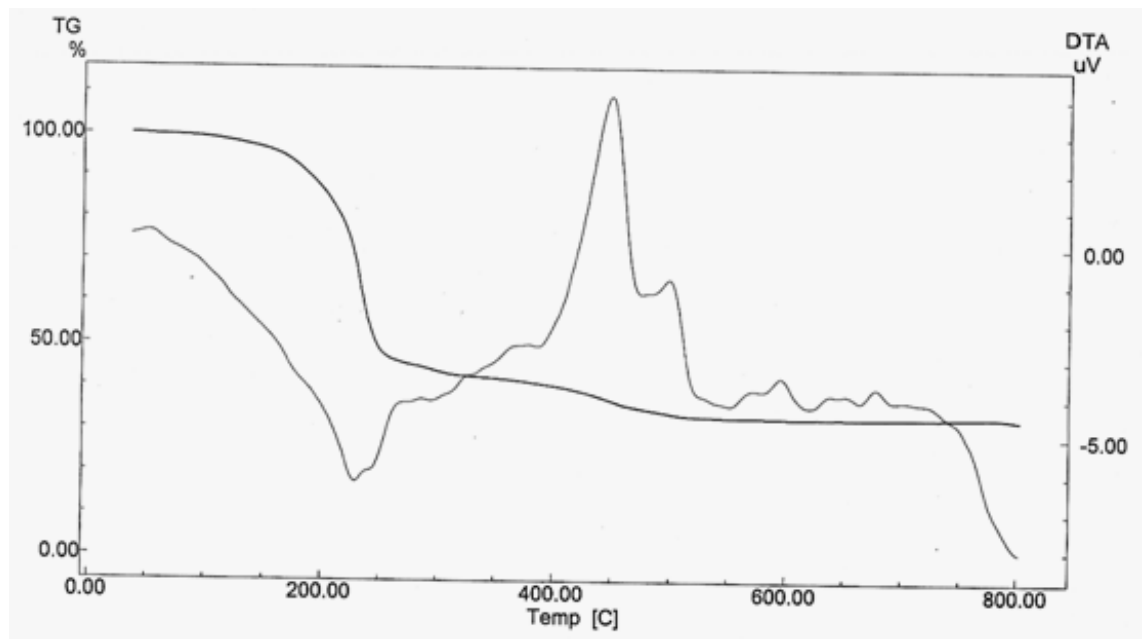

Fig. 8. Thermal analysis data and DTG of the Hg-OPTS complex.

\section{Conclusion}

The straight forward condensation of o-hydroxyphenyl azo acetyl acetone and thiosemicarbazide in 1:2 molar ratio to yield the novel bis( Schiff base) (2E,2'Z)-2,2'-(3-((E)-(2-hydroxyphenyl) diazenyl) pentane-2,4- diylidene) bis (hydrazinecarbothioamide) was reported. The compound is interesting in analytical chemistry and biology. Its composition and structure were determined by elemental analysis and IR spectrometry. Its flexible back bone, with the presence of $\mathrm{N}$ and $\mathrm{S}$ donor atoms, renders this compound important for studying its coordination behaviour with metal ions (Fig. 9). The compound presents in thione/thiol or both the tautomers forms. The interaction of OPTS with mercury (II) leads to the formation of a different type of complex. In this work, the dissociation constants of the reagent and the stability constants of their mercury complex were determined by $\mathrm{pH}$-metric and spectrometric titrations. The spectral data indicate that when equimolar amounts of ligand and mercury are used, the ligand can behave as a neutral tetradentate ligand to coordinate with a single metal ion through the $\mathrm{C}=\mathrm{N}$ and $\mathrm{C}$-SH groups. The coordinating behavior of bis(thiosemicarbazone) ligand establishes that it is the azomethine nitrogen and thiol sulphur which function as the donor sites toward the metal ion. 


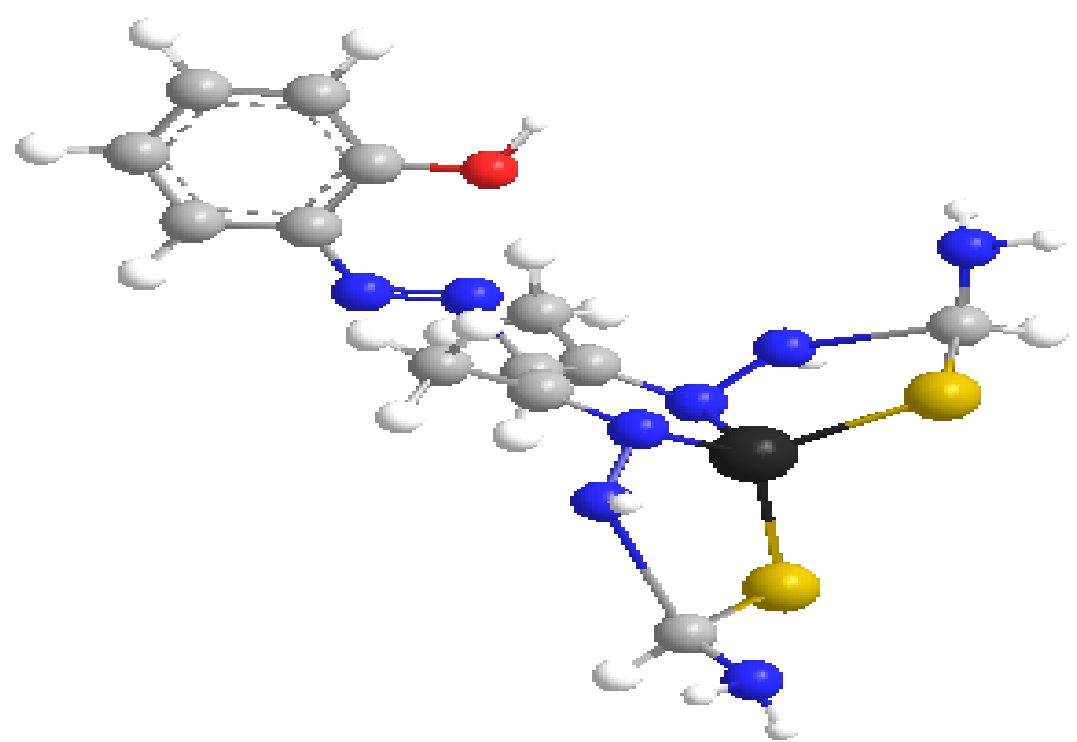

Fig. 9. ORTEP drawing of Hg-OPTS binary complex, showing their molecular structure and the labeling schemes used.

\section{References}

1. Domagk, G., Behnisch, R., Mietzsch, F. and Smidt, H., Naturwissenschaften, 33, 315(1946).

2. Zhong, X., Yi, J., Sun, J., Wei, H.-L., Liu, W.S. and Yu, K.B., Euro. J. Medi. Chem. 41 1090(2006).

3. Klayman, D. L., Bartosevich, J. F., Griffin, T. S., Mason, C. J. and Scovill, J. P., J. Med. Chem. 22, 855(1979).

4. Beraldo, H. and Gambino, D., Mini. Rev. Med. Chem. 4, 31(2004).

5. Wang, M. and Wang, L. F., Trans. Met. Chem. 26, 307(2001).

6. Clarke, C., Cowley, A.R., Dilworth, J.R. and Donnelly, P.S., J. Chem. Soc. Dalton Trans. 2402(2004).

7. Dhumwad, S.D., Gudasi, K.B. and Goudar, T. R., Indian J. Chem. A 33, 320 (1994).

8. Gulerman, N. N., Rollas, S., Erdeniz, H. and Kiraj, M. J. Pharm. Sci. 26, 1(2001).

9. Reddy, K.H., Reddy, P. S. and Babu, P. R., Trans. Met. Chem. 25, 154(2000).

10. Tarasconi, P., Capacchi, S., Pelosi, G., Cornia, M. , Albertini, R., Bonati, A., Dall, P. P., Lunghi, P. and Pinelli, S., Bioorg. Med. Chem. 8, 154(2000).

11. Singh, H., Yadav, L.D.S. and Mishra, S.B.S., J. Inorg. Nucl. Chem. 43, 1701(1981).

Egypt. J. Chem. 54, No.5 (2011) 
12. West, D.X., Dietrich, S.L.,Thientanavanich, I., Brown, C.A. and Liberta, A. E., Trans. Met. Chem. 19, 320(1994).

13. Chandra, S. and Sangeetika, Spectrochim. Acta: Part A 60, 147(2004) .

14. Akbar, M.A., Mirza, H.A., Monsur, A. and M. Nazimuddin, M., Polyhedron, 20, 1045(2001)

15. Klayman, D.L., Bartosevich, J.F., Griffin, T.S., Mason, C.J. and Scovill, J.P. J. Med. Chem. 22, 855(1979) .

16. Klayman, D. L., Scovill, J. P., Bartosevich, J. F. and Mason, C. J., J. Med. Chem. 22, 1367(1979).

17. Singh, N. K. and Singh, S. B., Indian J. Chem. A 40, 1070(2001).

18. Mishra,V., Pandeya, S. N. and Anathan, S., Acta Pharm. Turc. 42, 139(2000).

19. Singh, N. K. and Srivastava, A., Trans. Met. Chem. 25, 133(2000).

20. Vogel, A.I., "Practical Organic Chemistry" $3^{\text {rd }}$ ed., p. 998, Longmans London (1974).

21. Moustafa, M. H. , Abd-Almottaleb, M. , Seaf El-Naser, T. A., Issa, R. M. and Awad, A. M. A., Al-Azhar Bull. Sci. 15 (1), 243(2004).

22. Irving, H. and Rossotti, H.S., J. Chem. Soc. 2904(1954).

23. Ferrari, M. B., Capacchi, S., Bisceglie, F., Pelosi,G. and Tarasconi P., Inorg. Chim. Acta, 312, 81(2001).

24. Castineiras, A., Bermejo, E., Valdes-Martinez, J., Espinosa-Perez,G. and West, D. X., J. Mol. Struct. 522, 271(2000).

25. Kuban, V. and Havel, J., Acta Chem. Scand. 27, 528 (1973).

26. Phillips, J. P. and Merrit, L. L. , J. Am. Chem. Soc. 70, 410 (1948).

27. Sommer, L., Folia Fac. Sci. Nat. Uni. Purk., Brno, 5, 1(1964).

28. Gans, P., Sabatini, A. and Vacca, A., J. Chem. Soc., Dalton Trans. 1195(1985) .

29. Moustafa, M. H. , Al-Azhar Bull. Sci. (AISC'08), 71, March (2008).

30. Moustafa, M. H., Ass. Univ. Bull. Environ. Res. 13 (2), 77(2010).

31. Moustafa, M.H., Al-Azhar Bull. Sci. 12 (2), 295(2010).

32. Sommer, L., Kuban, V. and Havel, J., Folia Fac. Sci. Uni. Brno, Vol, XI, pt. 1, 33(1970).

33. Vozinca, P., Havel, J. and Sommer, L., Collec. Czech. Chem. Comm. 45 ,54 (1980). 
34. Abu-Baker,M.S., Rageh, H.M., Hashem, E.Y. and Moustafa, M. H., Monatsh. Chemi. 125, 1197(1994).

35. Job, P., Ann. Chem. 9, 113(1928).

36. Shirif, F. G. and Awad, A.M., Inorg. Nucl. Chem. 24, 79(1962).

37. Yoe, J. H. and Jones, H. L., Indian Eng. Chem., Anal. Ed., 16, 111(1944).

38. Sandell, E.P., "Colorimetric Determination of Trace Metals", Vol. 3, Wiley, New York, p. 97(1959) .

39. Das, M. K. , Nath, M. and Zuckerman, J. J., Inorg. Chem. Acta, 21, 49(1983).

40. El-Metwally, N.M., El-Shazly, R.M., Gabr, I.M. and El-Asmy, A.A., Spectrochim. Acta Part A, 61, 1113 (2005).

41. Du, K.K. and Liu, S.X., J. Mol. Struct. 874, 138(2008).

(Received 15/8/2011; accepted 10/4/2012) 


\section{تحضير وثبات وطيف وتوصيف متراكبات أيونات الزئبقيك الثنائى مع قاعدة شيف الجديدة \\ محمود حسن مصطفى ، أحمد عبد النعيم وأسامة أحمد عباس \\ قسم الكيمياء - كلية العلوم للبنين - جامعة الأزهر - فرع أسيوط - مصر.}

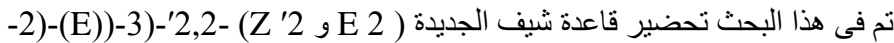

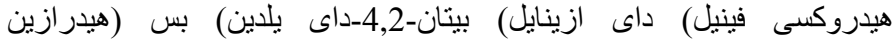

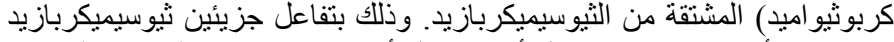

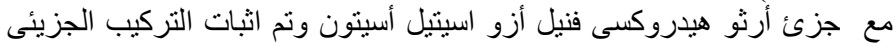

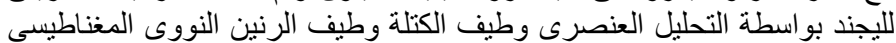

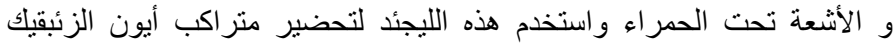

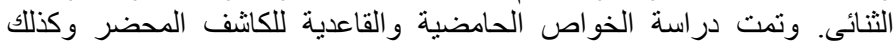

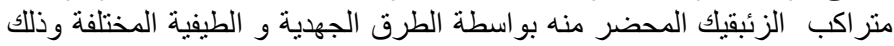

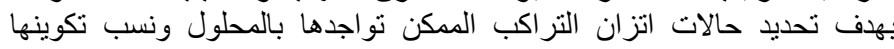

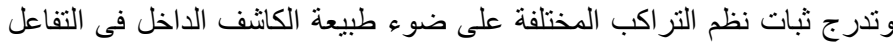

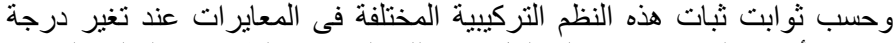

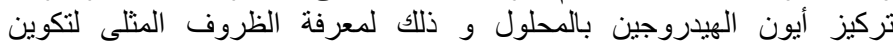

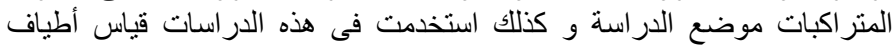

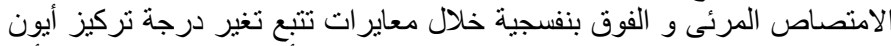

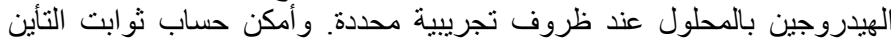

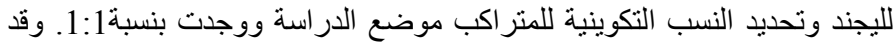

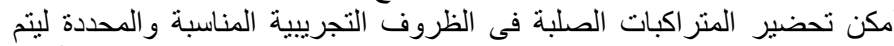

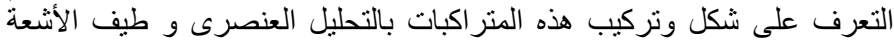

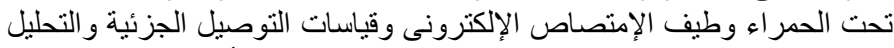

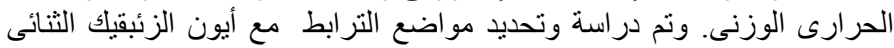
وتم التعرف على شكل وتركيب المتر اكب. 